\title{
Title: Development of a Malaysian Undergraduate Geriatric Medicine Curriculum
}

\section{Abstract}

Objective Malaysia is only beginning to age in 2020, but is expected to do this at an unprecedented rate in the next two decades. We aim to develop a national curriculum for undergraduate geriatric medicine in Malaysia to ensure future doctors are adequately equipped to address the healthcare needs of our older population.

Method The draft curriculum was developed by the Malaysian Society of Geriatric Medicine through literature review and mapping to the Malaysian Accreditation Guidelines for Undergraduate Medical Programme 2015. The curriculum was then refined through a modified Delphi process which involved 15 expert panel members each from Malaysia, Australia and the United Kingdom.

Results A total of three Delphi rounds were conducted. Five out of seven invited panellists agreed to participate in the first Delphi round. A larger group was invited via e-mail and fifteen panellists agreed to participate in Delphi rounds two and three, which resulted in 75 and 15 comments respectively. The final document with 34 learning outcomes was accepted with $80 \%$ agreement and consisted of detailed objectives grouped under 10 overarching core topics.

Conclusion Following consensus agreement determined through a Delphi process, a Malaysian undergraduate curriculum for geriatric medicine, aligned with the Malaysian Accreditation Guidelines, has been developed and will be shared with the 32 medical colleges in Malaysia to determine the current level of, and barriers to delivery. 


\section{Introduction}

Malaysia is an upper-middle income country in Southeast Asia with a multi-ethnic, multilingual, multicultural and multi-religious population of 32 million people. The country is comprised of 13 states and the Federal Territories comprising residents of more than 30 ethnic groups. Through population ageing, $7.2 \%$ ( 2.2 million) of its population will be over 64 years of age by 2020 . This number will rapidly treble by 2040 making it an aged nation by that time. Women and men aged 65 years in 2019 are expected to live another 17.1 and 14.8 years respectively(1). This increase in the number of older adults is associated with an increase in the prevalence of frailty, which is a state of poor homeostatic reserve which leads to increased vulnerability to adverse outcomes in the face of stressor events(2). Hence, it is expected that there will be an increase in the proportion of older inpatients with frailty which will present particular challenges around diagnosis and management(3). The dearth of undergraduate geriatric medical education in Malaysia was reported in the Teaching Geriatrics in Medical Education II Study conducted between March 2005 to August 2007 by the World Health Organization in which none of the Malaysian public medical schools participating and only one private medical school with a general medical curriculum provided the required data(4). Since then there has been no other additional publicly available data on the teaching of geriatrics in Malaysia.

As doctors who will be potentially manning the front lines of the national health care service, a firm grasp of the unique issues that are faced by the older Malaysian population is essential as the numbers of older people admitted to local hospitals are increasing(5). Older people often have complicated healthcare needs requiring comprehensive care(6). Therefore, health professionals should be equipped with the skills to manage complexity and the health system should be improved to cater for their needs(7). There are evidence-based approaches to care of older people, encapsulated within the literature on Comprehensive Geriatric 
Assessment, which have not been traditionally taught as part of medical curricula in different parts of the world(8)

Currently it is unclear what is taught about ageing in Malaysia in spite of the incorporation of care for the older people within the Guidelines for Accreditation of the Malaysian Undergraduate Medical Programme adopted by the Malaysian Medical Council in 2015(9). Where this issue has been addressed outside of Malaysia, the approach has been firstly to achieve consensus about what ought to be taught to undergraduates about ageing, then to survey what is taught, then to use this as a basis for improvement of teaching(10)(11). 


\section{Method}

Our methodology replicates processes used to develop Undergraduate Geriatric Medicine Curricula in the United Kingdom(12) and Europe(13). Following literature review, a modified Delphi process was carried out in which a panel of experts gave comments to identify, clarify, refine and finally gain consensus in a series of 'rounds'. The Delphi process is a well-recognized consensus method used to gauge agreement on a particular issue(14). Panellists were contacted separately via emails to avoid their opinions being influenced by others.

\section{Literature review and expert group}

A Grey Literature search revealed three main documents outlining core competencies in geriatric medicine, from each of the American Geriatric Society(15),the European Union of Medical Specialists(16) and the British Geriatric Society(12)(17). An expert group from the Malaysian Society of Geriatric Medicine (MSGM) adapted these for the Malaysian context and to remove duplication. The learning objectives of the MSGM curriculum were mapped to the Malaysian Accreditation Guideline for Undergraduate Medical Programme 2015(9).

\section{Delphi panel selection}

An initial smaller Delphi panel was selected from: 1) geriatricians in Malaysia who were identified based on the fact that they were currently working as geriatricians in Malaysia and had experience of teaching geriatric medicine to Malaysian undergraduates and (2) two external panellists comprising an academic geriatrician in Singapore and a Malaysian working as a geriatrician and teaching in an Australian medical school. The initial panel was intentionally small in order to pilot the invitation and feedback methods prior to extending 
the panel to include more national and international experts. Following this, the Delphi panel was then extended to academic and non-academic geriatricians in Malaysia as well as Malaysians working as academic and non-academic geriatricians abroad. As the pool of geriatricians in Malaysia was limited, the criteria for selection of panellists included those working as geriatricians in other countries but who had first-hand knowledge of the Malaysian culture and Malaysian medical schools.

\section{First Delphi Round}

Invited panel members received an e-mail with the 2015 Malaysian Accreditation Guideline, a pre-Delphi version of our geriatric medicine curriculum which had been mapped to the 2015 Malaysian Accreditation Guideline, a questionnaire and instructions on how to standardize the format of feedback given. As the Delphi technique is new to some nonacademics, an explanatory e-mail was also provided for clarification. Members were asked to respond to each paragraph of the pre-Delphi curriculum by stating whether they agreed with each paragraph or had suggestions for modification.

An anonymous internal report of the first Delphi rounds was tabulated and copied in full length. The expert group coordinators (H.S, M.P.T) evaluated these responses and contacted panelists individually for clarification of any ambiguity found. The first revision of the curriculum was then developed.

The guiding principles were adapted from Masud et al(16) which would take into consideration any relevant requests for improving clarity or wording, adding new aspects to an existing paragraph, deleting an aspect and lowering or increasing the difficulty level of existing objectives. The expert group ensured that any modification did not result in the omission of an objective that was considered relevant by the majority of the Delphi panel. 


\section{Second Delphi Round}

Potential members of a larger panel were initially contacted via e-mail. A full detailed report of the first Delphi round was then provided to all panel members which included the initial five members who participated in the first round. The same procedure of rating and analysis was applied.

\section{Third Delphi round}

All panel members were sent the full report of Delphi round 2 to determine if the statements were accepted or if there were any further disagreements. Feedback comments from the final round was incorporated according to the guiding principles. 


\section{Results}

\section{Participation of panel members}

Five out of seven panel members from Malaysia, Singapore and Australia who were invited, responded and completed the Delphi round 1. A further 15 panel members were invited and 10 responded for the next rounds, totaling 15 panel members for both Delphi rounds 2 and 3 . Panel members consisted of 11 geriatricians ( 8 from Malaysia, 2 from the United Kingdom, 1 from Australia), 3 academic geriatric trainees from Malaysia and 1 teaching fellow from Malaysia. All panel members were actively involved in medical care of older adults and twelve were involved in teaching medical students as a staff member or affiliate of a university.

\section{Analysis for the Delphi rounds}

The formulated pre-Delphi curriculum consisted of 17 learning outcomes. The Delphi round 1 managed to overcome small issues particularly in regards to the mapping to the Malaysian Guidelines for Accreditation document. Seventy-five feedback comments were received in Delphi round 2. Among the disagreements resolved were the following:

- Usage of the term "older person" rather than "elderly".

- Change of the core topics from "patient respect" to "respect for older persons", "common medical conditions" to "common geriatric conditions" and "multiple comorbidities" to "facilitating recovery and maximizing functions".

- Addition of more recent practice such as vaccination, awareness of elder abuse, combating ageism, patient-centred care and pain and suffering. 
- Addition of issues important to the Malaysian population such as traditional or complementary medicine, options of care and services available either public or private funded, challenges involved in leading a multidisciplinary team (particularly effective communication) and understanding different healthcare systems outside of Malaysia (UK, US, Australia, Singapore). This latter point was deemed important because of the number of Malaysians who train overseas and the need to adapt approaches from other countries to the Malaysian context.

Summary of the number of disagreements and general comments for each Delphi round are shown in Table 1.

Disagreements were highest in the Common Geriatric Conditions and the examples include "stroke" changed to "cerebrovascular disease, neurodegenerative disorders", "fluid balance" to "homeostasis" and "osteoporosis" to "bone health", addition of the phrase "and their significance in older adults" and addition of paragraph "adopt a patient-centred approach in formulation of management plans, including consideration of available resources and cost, while recognizing situations where precise diagnosis and disease modification is technologically possible but not necessary for the best interest of the patient or family".

Seventeen additional learning outcomes were added throughout the Delphi process. The learning outcomes for topics "respect for older persons" were expanded from 2 to 3 , "ageing principle" were kept at 3, "common geriatric conditions" were expanded from 1 to 3 , "comprehensive geriatric assessment" were expanded from 2 to 5, "medication use" were expanded from 2 to 5, "facilitating recovery and maximising function" were expanded from 2 to 3 , "ethical/legal issues" were expanded from 1 to 4 , "role of other health professions" were expanded from 1 to 3 , "healthcare in different settings" were expanded from 1 to 2 and "regional health and social care aspects" were expanded from 2 to 3. 
"Disagreement" was defined as the panel members giving feedback as an addition, deletion or merging of any sentence within the paragraphs. "General comments" was defined as the panel members re-phrasing a sentence or asking for clarification about a sentence. Summary of the Delphi process is shown in Figure 1.

\section{Consensus achieved}

Following the $3^{\text {rd }}$ Delphi round, twelve out of $15(80 \%)$ of the panel members agreed with the final version of the document. There were 7 disagreements as shown in Table 1 as the followings, which were appended to the paragraphs under core topics number 7, 9 and 10 as shown in Table 2:

(1) Addition of substitute decision makers and capacity assessment

(2) Addition of the types of elder abuse and understanding when it becomes a legal matter

(3) Introduction to advanced directives, power of attorney

(4) Introduction to orthogeriatric as an inpatient geriatric service

(5) Addition of teaching on outpatient specialty clinic or ambulatory services such as continence and falls

(6) Addition of after rehabilitation transition care services or intermediate care

(7) Addition of "students should be aware of the existence and roles of NGOs in the community".

\section{Final document}

The final document for the Malaysian Undergraduate Geriatric Medical Curriculum is shown in Table 2. It consists of 34 learning outcomes grouped under 10 identified core topics. 


\section{Discussion}

Malaysia is experiencing a rapid demographic shift with longer life expectancy and lower fertility rate, which is associated with an increased number of older adults with frailty. Increasing frailty is associated with complexity and multiple comorbidities leading to increased risk of institutionalization and death(18). Geriatric medicine interventions such as comprehensive geriatric assessment, medication reconciliation and multidisciplinary interventions have been shown to improve functional and mortality outcome(8). As Malaysia has increased its life expectancy by 20 years over the last six decades, from 54.3 years in 1957 to 74.5 years in 2019(1), it inevitably requires an evolution in the content of the undergraduate medical curriculum including emphasis on structured learning of medicine for the older person(10).

The development and implementation of this curriculum is timely and in-line with the Malaysian government's agenda as outlined in the Malaysian National Health Policy for Older Persons' (2008) goal to achieve optimal health for older persons through integrated and comprehensive health and health related services, the Malaysian Sustainable Development Goal based on United Nations indicators: Goal 3 (Good Health and Well-Being) and 4 (Quality and Life-Long Education) as well as promoting positive ageing and well-being for all as outlined in the 11th Malaysia Plan(19). Along with this, the current medical training must also take a paradigm shift in the way of teaching medicine from undergraduate through postgraduate level regardless of sub-specialties, to include ageing in the curriculum(20).

Based on the core topics outlined in this paper, medical schools are encouraged to develop their own teaching and learning modules(21).

The principles of the teaching of medicine for older persons differ from those of general internal medicine, which is to say that geriatric medicine is not merely general medicine in older adults. There are numerous reasons for this including the requirement to 
understand the physiological changes that occur with ageing; the non-specific presentation of illnesses in older people, the complexities of geriatric syndromes (including falls and cognitive issues)(22), and the way that psychological symptoms and diagnoses, such as depression, contribute to illness in older persons. An understanding of the comprehensive geriatric assessment (CGA)(23) is core to effective care of older people. CGA is a holistic evaluation of physical, functional, psychological, social and environmental aspects of an older adult, and involves a multi-disciplinary approach that includes treatment and rehabilitation planning. Teaching such a complex concept requires time, clinical exposure for contextualisation and input from multiple professions. Other geriatric medicine specific issues include: the challenge in obtaining a comprehensive history and physical examination from an older patient; and legal and ethical responsibilities with regards to older persons including issues such as elder abuse(24), elder neglect and end of life decision making.

There are reasons that curricula around ageing may legitimately vary between countries(25). Care of older people is multidisciplinary and cultural, and legal and ethical issues can lead to significant differences in what ought to be taught. Within Malaysia, for example, important differences include the structure of the Malaysian health care system(26)'(27), the diverse multi-racial population with multiple beliefs and perceptions regarding ageing and health, local legal frameworks, and the availability of resources and social support systems for the ageing citizen(28). Orthogeriatric is still regarded as an innovation in Malaysia, whilst specialty outpatient clinics for continence and falls are in their infancy. It is more difficult to argue for the inclusion of these topics in undergraduate teaching whilst they are seen as a highly specialised, than it might be in European countries where they are more established. This is an example of how an undergraduate curriculum will have to be a dynamic document, taking accounts of changing trends in service delivery and care as geriatric medicine in Malaysia develops. Legal frameworks around older persons in 
Malaysia are jurisdiction-specific, for example advanced care planning is not legally bound and there is no legal act on safeguarding the older adults or elder abuse(29)(30). The subject of assisted dying is an important subject for older adults who are perceived in intense suffering. It is not legal in Malaysia and is included in our curriculum, based on consensus, to spark discussion about what is happening worldwide and what are the lessons on this ethically controversial subject.

\section{Conclusions and future research}

We have developed a Malaysian undergraduate curriculum for geriatric medicine which is aligned with the Malaysian Accreditation Guideline for Undergraduate Medical Programme 2015. The curriculum shares fundamental core topics with previously published undergraduate geriatric medicine curricula from the UK, US and Europe, but there are nationspecific differences related to legal frameworks, end of life care, assisted dying, advanced care planning and national policies. The curriculum will now be shared with the 32 medical colleges in Malaysia to establish the extent to which they are currently taught and the barriers to delivery. 
Competing interest None declared

Funding The authors have not declared a specific grant for this research from any funding agency in the public, commercial or not-for-profit sectors. This project is supported by the Malaysian Society of Geriatric Medicine in terms of allowing the usage of their logo in communications with the medical schools.

\section{Acknowledgement}

We thank the following panel members who participated in the Delphi process and agree with the final version of the curriculum: Lee Fatt Soon (former Head of National Geriatric Service, Malaysia), Rizah Mazzuin Razali, Elizabeth Chong Gar Mit (Hospital Kuala Lumpur, Malaysia), Seenikatty Abdul Hakim (University Hospital Wishaw, Lanarkshire Trust Scotland), Tan Maw Pin, Khor Hui Min, Nor Izzati Saedon (University of Malaya, Malaysia), Hakimah Sallehuddin (University Putra Malaysia, Malaysia), Nur Aimy Abdullah, Noor Azleen Ahmad Tarmidzi, (University Teknologi Malaysia, Malaysia), Deepa Alex (Monash University Malaysia), Terence Ong, Poon Mun Hoe (Nottingham University Hospitals NHS Trusts, United Kingdom), Loh Pei Chong (Lam Wah Ee Hospital, Malaysia) and Renuka Visvanathan (University of Adelaide, Australia). Participating panel members expressed their personal opinions which might not reflect the position of the institutions they represent. We also thank Ms Irene Lim from the Malaysian Society of Geriatric Medicine who was involved in the initial literature review and assisted in proof-reading the documents.

\section{Ethics approval}

After discussion with Putra Malaysia University's Ethics Committee, ethical approval was deemed unnecessary for this paper as it assessed teaching provision against a nationallyaccredited guidelines. 


\section{References}

1. Department of Statistics Malaysia Official Portal [Internet]. [cited 2020 Jan 15]. Available from:

https://www.dosm.gov.my/v1/index.php?r=column/cthemeByCat\&cat=116\&bul_id= YnV4S1FyVnNzUWJIQ3F5NHVMeFY3UT09\&menu_id=LOpheU43NWJwRWVSZkIWdzQ 4TIhUUT09

2. Xue QL. The Frailty Syndrome: Definition and Natural History. Vol. 27, Clinics in Geriatric Medicine. 2011. p. 1-15.

3. Theou O, Squires E, Mallery K, Lee JS, Fay S, Goldstein J, et al. What do we know about frailty in the acute care setting? A scoping review. Vol. 18, BMC Geriatrics. BioMed Central Ltd.; 2018.

4. WHO | Teaching geriatrics in the medical education II. WHO. 2015;

5. Amin M, Mokhtar M, Pin TM, Zakaria MI, Hairi NN, Kamaruzzaman SB, et al. Utilization of the emergency department by older residents in Kuala Lumpur, Malaysia.

6. Ambigga KS, Ramli AS, Suthahar A, Tauhid N, Clearihan L, Browning C. Bridging the gap in ageing: Translating policies into practice in Malaysian Primary Care. Asia Pac Fam Med. 2011 Mar 8;10(1):2.

7. Yunus NM, Manaf NHA, Omar A, Omar MA, Salleh M. Determinants of Healthcare Utilisation among the Elderly in Malaysia. Institutions Econ. 2017 Jul 28;115-40.

8. Ellis G, Gardner M, Tsiachristas A, Langhorne P, Burke O, Harwood RH, et al. Comprehensive geriatric assessment for older adults admitted to hospital. Vol. 2017, Cochrane Database of Systematic Reviews. John Wiley and Sons Ltd; 2017.

9. Malaysian Medical Council. Guidelines For Accreditation of The Malaysian 
Undergraduate Medical Education Programme [Internet]. 2015 [cited 2018 Feb 28]. Available from: http://www.mmc.gov.my/index.php/accreditation-guidelines

10. Gordon AL, Blundell AG, Gladman JRF, Masud T. Are we teaching our students what they need to know about ageing? Results from the UK National Survey of Undergraduate Teaching in Ageing and Geriatric Medicine. Age Ageing. 2010 May $1 ; 39(3): 385-8$.

11. Bardach SH, Rowles GD. Geriatric education in the health professions: Are we making progress? Gerontologist. 2012 Oct;52(5):607-18.

12. Forrester-Paton C, Forrester-Paton J, Gordon AL, Mitchell HK, Bracewell N, Mjojo J, et al. Undergraduate teaching in geriatric medicine: mapping the British Geriatrics Society undergraduate curriculum to Tomorrow's Doctors 2009. Age Ageing. 2014 May 1;43(3):436-9.

13. Masud T, Blundell A, Gordon AL, Mulpeter K, Roller R, Singler K, et al. European undergraduate curriculum in geriatric medicine developed using an international modified Delphi technique. Age Ageing. 2014 Sep;43(5):695-702.

14. Vernon W, Vernon W. The Delphi technique: A review. Int J Ther Rehabil. 2009;16(2):69-76.

15. The Education Committee Writing Group of the American Geriatrics Society. Core Competencies for the Care of Older Patients: Recommendations of the American Geriatrics Society. Acad Med. 2000;75(3):252-5.

16. Masud T, Blundell A, Gordon AL, Mulpeter K, Roller R, Singler K, et al. European undergraduate curriculum in geriatric medicine developed using an international modified Delphi technique. Age Ageing. 2014 Sep 1;43(5):695-702.

17. The BGS Recommended Curriculum in Geriatric Medicine for Medical Undergraduates 
| British Geriatrics Society [Internet]. [cited 2019 Oct 25]. Available from:

https://www.bgs.org.uk/resources/the-bgs-recommended-curriculum-in-geriatricmedicine-for-medical-undergraduates

18. Rockwood K, Howlett SE, MacKnight C, Beattie BL, Bergman H, Hébert R, et al. Prevalence, attributes, and outcomes of fitness and frailty in community-dwelling older adults: Report from the Canadian Study of Health and Aging. Journals Gerontol Ser A Biol Sci Med Sci. 2004;59(12):1310-7.

19. Economic Planning Unit PMD. Eleventh Malaysia Plan, 2016-2020 [Internet]. [cited 2018 Feb 25]. Available from: http://www.epu.gov.my/en/rmk/eleventh-malaysiaplan-2016-2020

20. Ebrahim S. Demographic shifts and medical training. Br Med J. 1999 Nov 20;319(7221):1358-60.

21. Tullo ES, Spencer J, Allan L. Systematic review: Helping the young to understand the old. Teaching interventions in geriatrics to improve the knowledge, skills, and attitudes of undergraduate medical students. Vol. 58, Journal of the American Geriatrics Society. 2010. p. 1987-93.

22. Morley JE. The New Geriatric Giants. Vol. 33, Clinics in Geriatric Medicine. W.B. Saunders; 2017. p. xi-xii.

23. Welsh TJ, Gordon AL, Gladman JR. Comprehensive geriatric assessment - A guide for the non-specialist. Vol. 68, International Journal of Clinical Practice. Wiley-Blackwell; 2014. p. 290-3.

24. Sooryanarayana R, Choo WY, Hairi NN, Chinna K, Bulgiba A. Insight into elder abuse among urban poor of Kuala Lumpur, Malaysia - A middle-income developing country. Vol. 63, Journal of the American Geriatrics Society. Blackwell Publishing Inc.; 2015. p. 
$180-2$.

25. Blundell A, Gordon A, Gladman J, Masud T. Undergraduate Teaching in Geriatric Medicine: The Role of National Curricula. Gerontol Geriatr Educ. 2009 Feb $13 ; 30(1): 75-88$.

26. Thomas S, Beh L, Nordin R Bin. Health care delivery in Malaysia: Changes, challenges and champions. J Public Health Africa. 2011;2(2):93-7.

27. Poi PJH, Forsyth DR, Chan DKY. Services for older people in Malaysia: Issues and challenges. Vol. 33, Age and Ageing. 2004. p. 444-6.

28. Tan M, Kamaruzzaman S, Poi P. An Analysis of Geriatric Medicine in Malaysia-Riding the Wave of Political Change. Geriatrics. 2018 Nov 15;3(4):80.

29. LAWS OF MALAYSIA Power of Attorney Act 1949 (Act 424).

30. Balasingam U, Dhanapal S, Sabaruddin JS, Nazeri NBM. A need for enduring power of attorney in Malaysia. Adv Sci Lett. 2017 Sep 1;23(9):9060-4. 
